\title{
A novel technique for peroral direct cholangioscopy
}

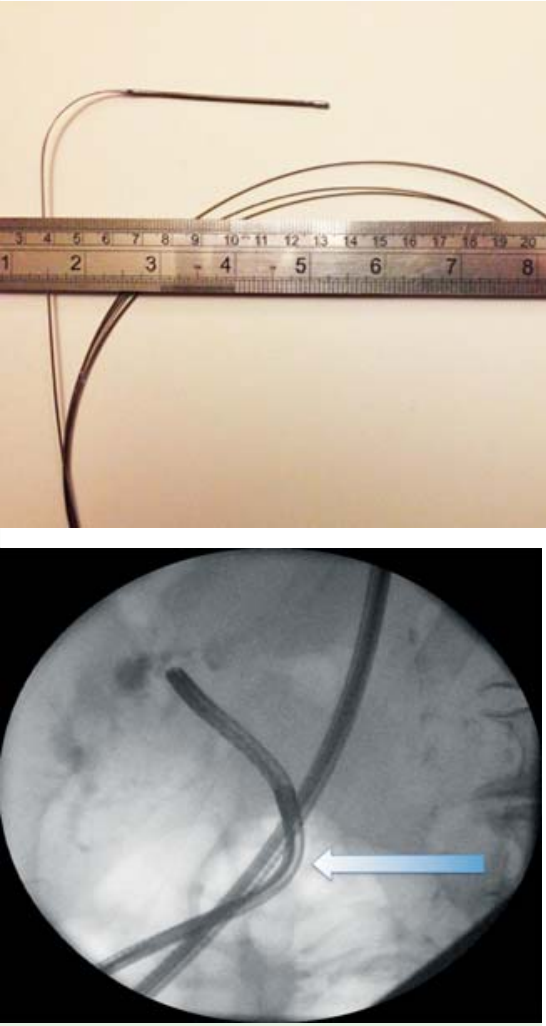

Fig. 2 The nasendoscope in position in the common bile duct (CBD) with the pre-bent wire still in place (arrow). The wire is subsequently removed to allow biopsy and flushing.

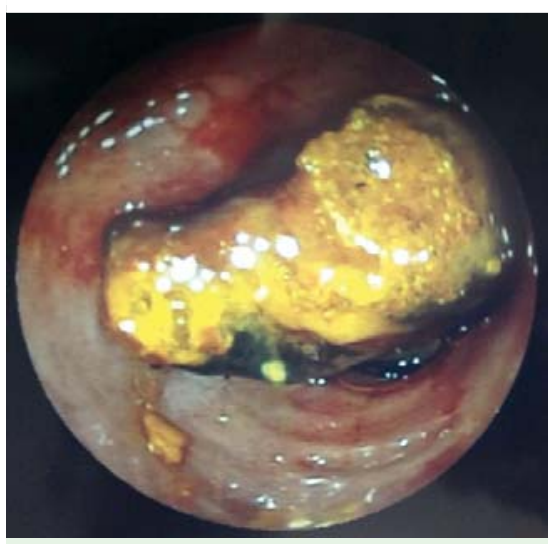

Fig. 4 A ductal stone still in place following a balloon trawl.

Direct cholangioscopy has been possible since the 1970s [1] but the reliability of the intubation of the common bile duct (CBD) and second-order ducts has limited the applicability of the technique. One of the limitations to accessing the ducts is the acute angulation between the duodenum and the CBD [2]. Various methods
Fig. 1 A typical bend in both the flexible and stiff end of a stiff wire.
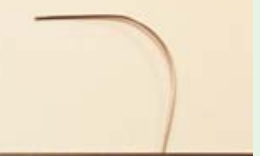

.
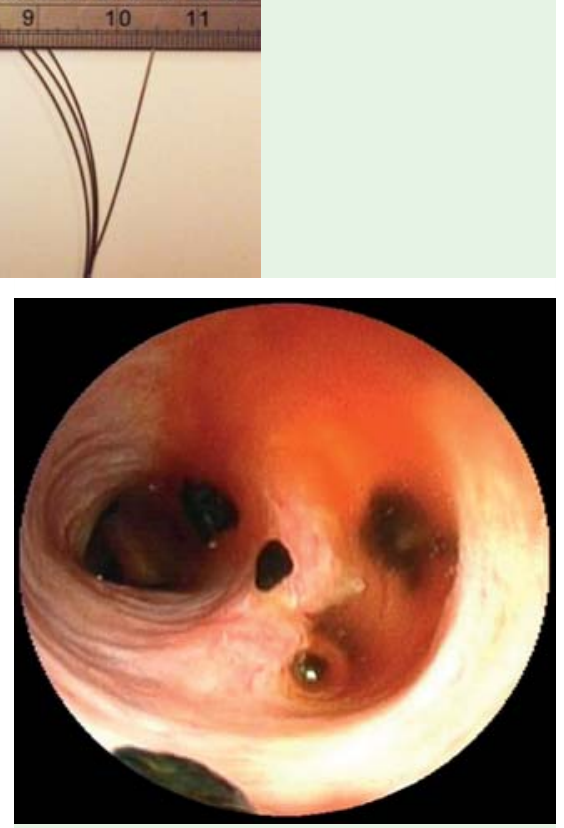

Fig. 3 Second-order ducts, stone remnants, and mucus.

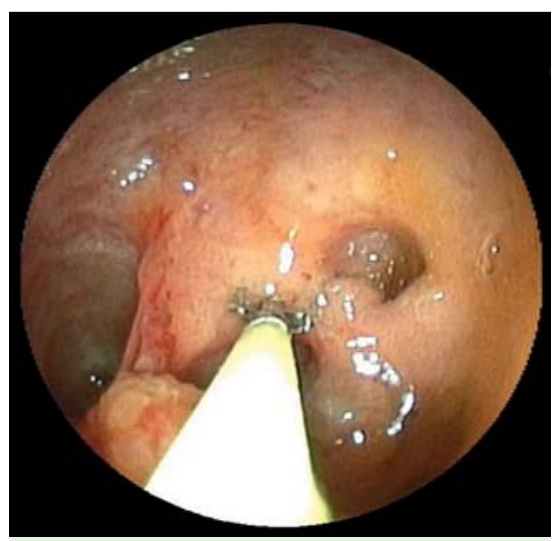

Fig. 5 Biopsy forceps in position.

have been employed to access the ducts including mother-and-baby endoscopes and balloon assisted intubation [3]. Motherand-baby systems are expensive, require additional equipment, and provide poorer quality images than standard endoscopes. Balloon-assisted intubation carries a risk of damage to the $\mathrm{CBD}$, and requires specia- list equipment with an associated learning curve [4].

We have developed a novel technique that involves the use of a standard stiff wire (SMGW, Marflow AG, Switzerland) bent to the angulation of the duodenum-CBD junction ( $\bullet$ Fig. 1 ) and passed through the working channel of a standard 5.6- $\mathrm{mm}$ Olympus nasendoscope. The technique begins after endoscopic retrograde cholangiopancreatography (ERCP) and sphincterotomy with a nasendoscope passed orally into the duodenum with the tip directed at the sphincter of Oddi. A prebent stiff wire is passed through the working channel until the bend in the wire sits within the flexible portion of the endoscope. The nasendoscope is then railroaded over the pre-bent wire into the CBD by advancing the nasendoscope whilst holding the wire fixed ( Fig. 2 ). Once the flexible portion of the nasendoscope is completely within the $\mathrm{CBD}$, the wire can be removed to allow full use of the working channel.

Using this technique, we have successfully intubated second-order ducts ( $\bullet$ Fig.3) and have been able to make reliable in vivo diagnosis using high definition endoscopes, remove difficult stones ( $\bullet$ Fig.4), and biopsy lesions ( $\bullet$ Fig.5) under direct vision without complications. The advantages of our technique are its low cost, that no additional equipment is required, and that it has a short learning curve. More research is needed into the technique to determine its limits and the associated risks.

Endoscopy_UCTN_Code_TTT_1AR_2AB

Competing interests: None

Jim L. Callaghan, Gaius LongcroftWheaton, Andrew J. Fowell, Richard D. Ellis, Pradeep Bhandari, Patrick M. Goggin

Department of Gastroenterology, Queen Alexandra's Hospital, Cosham, Portsmouth, PO6 3LY, UK

\section{References}

1 Urakami Y. Peroral cholangiopancreatoscopy (PCPS) and peroral direct cholangioscopy (PDCS). Endoscopy 1980; 12: 30-37

2 Waxman I, Dillon T, Chmura K et al. Feasibility of a novel system for intraductal balloonanchored direct peroral cholangioscopy and endotherapy with an ultraslim endoscope (with videos). Gastrointest Endosc 2010; 72: $1052-1056$ 
3 Moon JH, Ko BM, Choi HJ et al. Intraductal balloon-guided direct peroral cholangioscopy with an ultraslim upper endoscope (with videos). Gastrointest Endosc 2009; 70: 297-302

4 Pohl J, Ell C. Direct transnasal cholangioscopy with ultraslim endoscopes: a one-step intraductal balloon-guided approach. Gastrointest Endosc 2011; 74: 309-316
Bibliography

Dol http://dx.doi.org/

10.1055/s-0034-1390921

Endoscopy 2014; 46: E672-E673

(c) Georg Thieme Verlag KG

Stuttgart · New York

ISSN 0013-726X
Corresponding author

Patrick M. Goggin, MD

Queen Alexandra's Hospital Luminal Gastroenterology

Southwick Hill Road

Cosham

Portsmouth PO6 3LY

UK

Fax: +44-23-92286303

Patrick.goggin@porthosp.nhs.uk 